TABLE I.

Comparison of content of summaries between May 1990 and May 1991

\begin{tabular}{|c|c|c|c|c|}
\hline \multirow[t]{2}{*}{ Item } & \multicolumn{4}{|c|}{ No. of summaries in which item is present } \\
\hline & \multicolumn{2}{|c|}{1990} & \multicolumn{2}{|c|}{1991} \\
\hline Reason for admission & 29 & $(100 \%)$ & 20 & $(68 \%)$ \\
\hline Progress on ward & 24 & $(83 \%)$ & 20 & $(70 \%)$ \\
\hline Diagnosis & 29 & $(100 \%)$ & 32 & $(100 \%)$ \\
\hline ICD-9 Code & 0 & $(0 \%)$ & 27 & $(84 \%)$ \\
\hline Investigations & 21 & $(72 \%)$ & 10 & $(31 \%)$ \\
\hline Information to & & & & \\
\hline patients \& relatives & 0 & $(0 \%)$ & 26 & $(81 \%)$ \\
\hline Prognosis & 0 & $(0 \%)$ & 31 & $(97 \%)$ \\
\hline Follow-up & 27 & $(93 \%)$ & 29 & $(91 \%)$ \\
\hline Medication & 29 & $(100 \%)$ & 32 & $(100 \%)$ \\
\hline
\end{tabular}

compared with a mean of four days in 1991. In 1990, $10 \%$ of summaries took over 13 days to be completed compared with $2 \%$ in 1991 . Table I compares the content of the summaries between the two years.

\section{Comments}

Any such study over short, well-defined periods of time will be influenced by the individual junior doctors completing the summaries. It may be useful to repeat the procedure using a different set of staff. However, it is hoped that the set format and the plan to complete it during the ward round will go towards standardising this. Also the study does not take into account possible delay in signing the typed summary, or the time taken for it to reach the GP after signing.

Another consideration would be whether filling in this form during a ward round significantly increases its length. We have found that it can, at most, add five to ten minutes per patient, but this would presumably be much less time than the junior doctor would otherwise spend completing it alone. Also for the less experienced junior doctor it could be seen as a useful learning experience.

The context of the new summary was improved in that it contained the prognosis and stated whether information had been imparted to patients and their relatives, although the extent of this information was not usually stated. However, there was less mention of why the patient had been admitted and what investigations had been carried out.

\section{Recommendations}

This study has demonstrated an improvement in the efficiency of completion of discharge summaries. However as with any audit exercise, actually looking at the effect of action, i.e. changing the format of the summary, has shown up other deficiencies. We therefore intend to revise our format to include the headings 'Reason for Admission' and 'Investigations Undergone'.

\title{
Use of College Reception Rooms
}

Council has agreed that the College receptions room should be made available to members for social functions such as wedding receptions, retirement parties, anniversary dinners etc.

Any member wishing to obtain further details about hiring these facilities, should contact $\mathrm{Mr}$
Francis Bloomfield, Office Services Manager at the College.

VANessa CAMERoN The Secretary 